Communications in Physics, Vol. 24, No. 3 (2014), pp. 267-273

DOI:10.15625/0868-3166/24/3/4231

\title{
STUDY OF TEMPERATURE EFFECT ON LUMINOUS FLUX OF HIGH POWER CHIP-ON-BOARD LIGHT EMITTING DIODE
}

\author{
CAO XUAN QUAN AND VU KHANH XUAN \\ Photometry and Radiometry Laboratory, Vietnam Metrology Institute \\ LUU THI LAN ANH AND VO THACH SON \\ School of Engineering Physics, Hanoi University of Science and Technology \\ E-mail: quancx@vmi.gov.vn
}

Received 25 July 2014

Accepted for publication 21 August 2014

\begin{abstract}
High power chip-on-board light emitting diode (HPCOBLED) is a promising solid state light technology for a variety of lighting applications. In this paper, we study temperature effect on luminous flux of HPCOBLED using VMI-PR-001 system of Vietnam Metrology Institute. The results show that when the case temperature $\left(T_{c}\right)$ increases, luminous flux decreases. In particular, when HPCOBLED is of high power, the decrease of luminous flux is larger. An explanation for this result is consumed power on the LED. We proposed HPCOBLED model modified from Hodapp's model using temperature gradient between $p$ - $n$ junction of device and heat radiator for description of the temperature effect on luminous flux of HPCOBLED. The calculation results for the modified HPCOBLED model match with those experimental values measured by the luminous flux measurement system (VMI-PR-001, Vietnam).
\end{abstract}

Keywords: high power chip-on-board light emitting diode (HPCOBLED), luminous flux, integrating sphere.

\section{INTRODUCTION}

High power chip-on-board light emitting diode (HPCOBLED) is a big potential candidate for solid state lighting technology in a variety of applications, including indoor and decorative lighting, street lamps, and automotive lighting [1-5]. HPCOBLED presents several advantages over conventional lighting technologies such as follows: (i) long operation lifetime, (ii) low energy consumption, and (iii) environmental protection.

However, the actual efficiency and performance of HPCOBLED are highly depended on their operating temperature, which is an important issue due to possible overheating, even under normal operating conditions. In addition, the most critical thermal effects on HPCOBLED are reduction in operation lifetime, shifts of the emitted wavelength, and lower operational efficiency [6-9].

In this paper we present the research results of the temperature influence on the luminous flux of HPCOBLED, which is searched by evaluating the temperature dependence of the luminous flux of four different power HPCOBLEDs. The relationship between the case temperature and the luminous flux of the HPCOBLED is described by modified high-power LED model based on 
thermal transportation with different thermal resistances from p-n junction to case of solid- state lighting device. The calculation result using modified HPCOBLED is very well matched with experiment.

\section{EXPERIMENTS}

\section{II.1. Experiment setup}

In our study, we used HPCOBLEDs of models NSCWL036A-5 W, NSBWL066A-10 W, NSBWL121A-20 W and NSCWJ216A-35 W produced by Nichia, Japan [10]. The HPCOBLED were measured at the case temperatures, $T_{c}$, from $25^{\circ} \mathrm{C}$ to $100^{\circ} \mathrm{C}$. The HPCOBLED was mounted on a thermoelectric cooler (TEC mount 284) to keep the HPCOBLED operation temperature stable as shown in the Fig. 1a.

The luminous flux was measured by the VMI-PR-001 system of Vietnam Metrology Institute (see Fig. 1.b)

Temperature distribution of HPCOBLEDs at different temperatures was recorded by infrared (IR) camera (Ti32-12020008, Flux-USA).
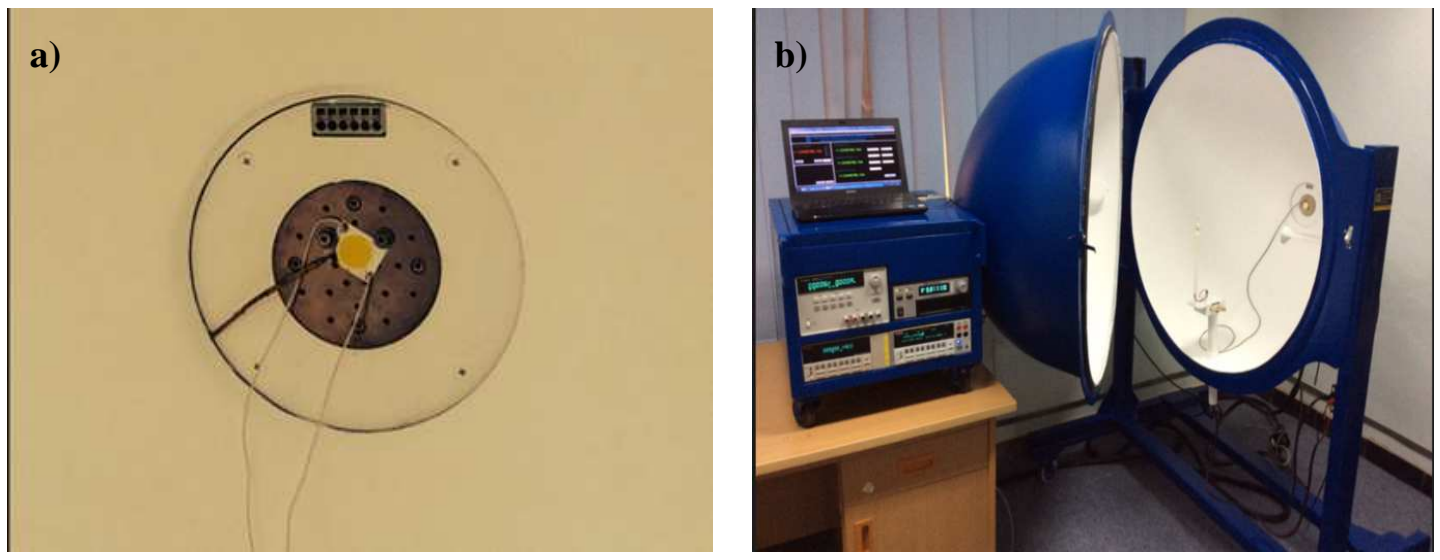

Fig. 1. (a) HPCOBLED mounted on a thermoelectric cooler (TEC), and (b) VMI-PR-001 system for luminous flux investigation

\section{II.2. Modified HPCOBLED model}

Fig. 2 presents a simple thermal transportation model for HPCOBLED. As seen from figure 2 the heat generated by HPCOBLED in operation has released from the heat generation place in HPCOBLED (commonly at p-n junction of the device) directly to the case and to ambient. This model is acceptable if the thermal transportation from the HPCOBLED to ambient by convection and radiation are neglected $[8,12]$.

It is noticed here that: $T_{j}$ is the junction temperature of HPCOBLED, $T_{c}$ is the case temperature of HPCOBLED, Ta is the ambient temperature, $R_{j-c}$ is the thermal resistance from junction to case of HPCOBLED, Rc-a is thermal resistance between the case and ambient. In addition, $T_{j}>T_{c}>T_{a}$.

Assumptions of the HPCOBLED model are followings: 
i) Heat conduction process occurs only in one direction, which is perpendicular to the substrate surface (thermal convection and radiation are neglected).

ii) HPCOBLED is composed of multiple discrete LEDs and characterized by a high power LED

iii) Elimination of the thermal interaction between the discrete LEDs.

iv) $25^{\circ} \mathrm{C} \leq T_{c} \leq T_{c_{\max }}$.

v) $P\left(T_{c}=25^{\circ} \mathrm{C}\right)$ is keeping constantly as referent consumption power.

vi) $T_{c}=T_{j}-R t h_{j-a} . P$.

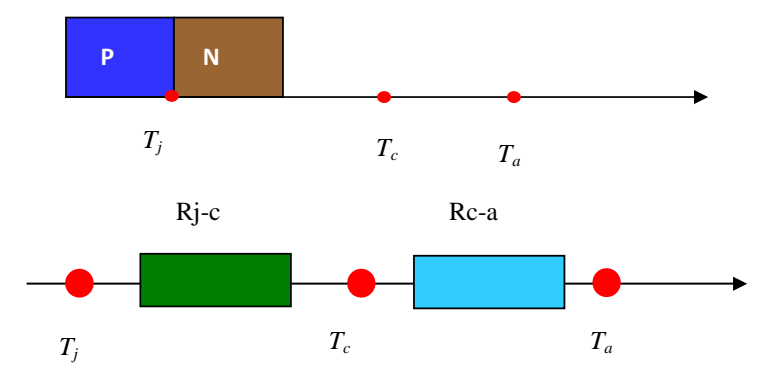

Fig. 2. Thermal model for temperature distribution of the HPCOBLED

The propose HPCOBLED model is modified from Hodapp's model [11] to take into account the case of the formation of the temperature gradient in the perpendicular direction to the substrate surface. Temperature gradient $(\Delta T)$ of HPCOBLED caused by different thermal resistances from p-n junction of device to ambient characterizes the decrease in power when temperature rises. Therefore, the temperature gradient of HPCOBLED can be expressed in the following equation:

$$
\Delta T=R c-a . \Delta P
$$

where $\Delta P=P\left(T_{c}=25^{\circ} \mathrm{C}\right)-P\left(T_{c}\right)$ is difference of consumption powers at real and referent powers of HPCOBLED, measured by U.I; $\mathrm{P}\left(T_{c}=25^{\circ} \mathrm{C}\right)$ and $P\left(T_{c}\right)$ are the consumption powers at $T_{c}=$ $25^{\circ} \mathrm{C}$ and at temperature $T_{c}$, respectively

The luminous flux of HPCOBLED as a function of $T_{C}$ temperature is represented as follows:

$$
\Phi_{v}(T)=\Phi_{v}\left(T=25^{\circ} \mathrm{C}\right) e^{k\left(T+\Delta T-25^{\circ} \mathrm{C}\right)}
$$

\section{RESULTS AND DISCUSSION}

Fig. 3 shows the luminous flux of HPCOBLEDs at different case temperatures, which experimentally measured by VMI-PR-001 system. In general, the luminous flux of HPCOBLEDs reduces as temperature increases for all kind of devices. From Fig. 3 we can see that slope of the reduction of luminous flux depends on operation power of the devices. The slope of reduction of luminous flux would be increased when the consumption power is higher. Experiment shows that when case temperature $T_{c}$ increases, the voltage on the HPCOBLED decreases while the current $I_{f}$ is constant. Therefore, consumed power is reduced when increasing the case temperature, and then, the luminous flux is reduced. 


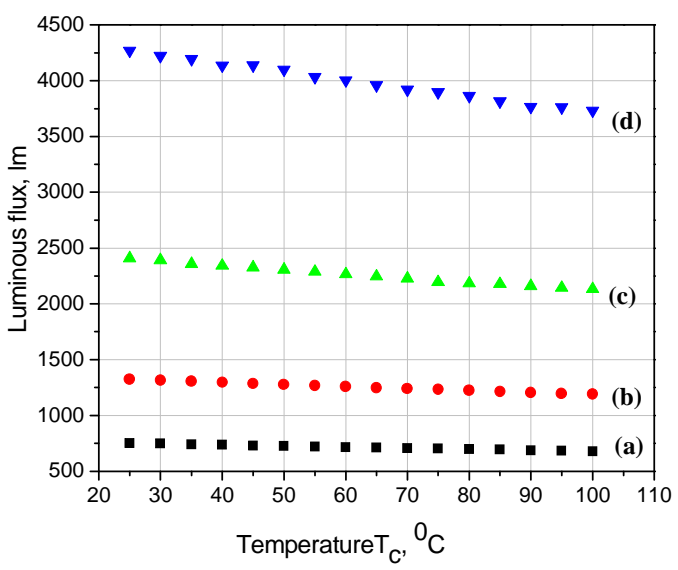

Fig. 3. Graph of the luminous flux of HPCOBLEDs at different case temperatures: a) $5 \mathrm{~W}, \mathrm{~b}) 10 \mathrm{~W}, \mathrm{c}) 20 \mathrm{~W}$ and d) $35 \mathrm{~W}$

Fig. 4 shows the temperature distribution at $T_{c}=55^{\circ} \mathrm{C}$ for HPCOBLEDs with different consumption powers, which is recorded by infrared camera. We can see that, temperature distribution of HPCOBLED is quite different and it strongly depends on the consumption power of devices. For $35 \mathrm{~W}$-HPCOBLED the case temperature can reach up to $117^{\circ} \mathrm{C}$ while for $5 \mathrm{~W}$-device this one is only of $80^{\circ} \mathrm{C}$.
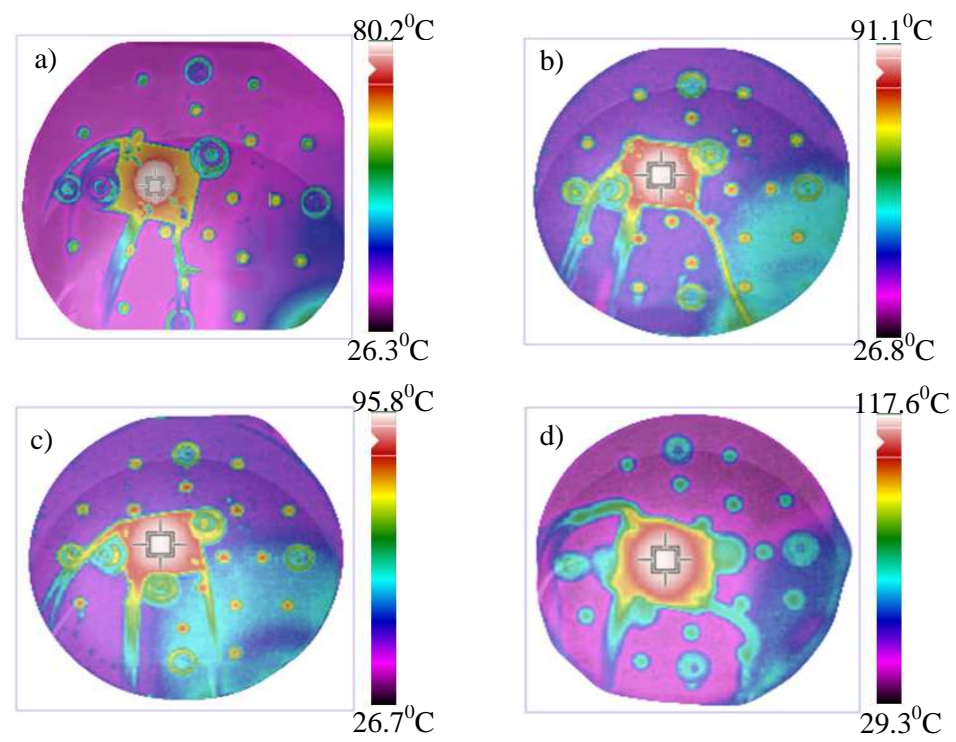

Fig. 4. Image of temperature distribution of HPCOBLEDs at $T_{c}=55^{\circ} \mathrm{C}$ a) $5 \mathrm{~W}$, b) $10 \mathrm{~W}$, c) $20 \mathrm{~W}$ and d) $35 \mathrm{~W}$ 
The measured temperatures of different consumption power HPCOBLEDs are presented in the Table 1. The temperature difference $\Delta T$ of devices increased with increase of consumption power (from $22.4^{\circ} \mathrm{C}$ for $5 \mathrm{~W}$ to $69.5^{\circ} \mathrm{C}$ for $35 \mathrm{~W}$ ), the temperature gradient of the device would be larger with higher consumption power.

Table 1. Temperature difference of HPCOBLED

\begin{tabular}{|c|c|c|c|c|c|c|c|c|}
\hline \multirow{4}{*}{$T_{c}\left({ }^{\circ} \mathrm{C}\right)$} & \multicolumn{8}{|c|}{ HPCOBLED, P(W) } \\
\cline { 2 - 9 } & \multicolumn{2}{|c|}{5} & \multicolumn{2}{c|}{10} & \multicolumn{2}{c|}{20} & \multicolumn{2}{c|}{35} \\
\cline { 2 - 9 } & $\begin{array}{c}\mathrm{T} \max \\
\left({ }^{\circ} \mathrm{C}\right)\end{array}$ & $\begin{array}{c}\Delta \mathrm{T} \\
\left({ }^{\circ} \mathrm{C}\right)\end{array}$ & $\begin{array}{c}\mathrm{T} \max \\
\left({ }^{\circ} \mathrm{C}\right)\end{array}$ & $\begin{array}{c}\Delta \mathrm{T} \\
\left({ }^{\circ} \mathrm{C}\right)\end{array}$ & $\begin{array}{c}\operatorname{Tmax} \\
\left({ }^{\circ} \mathrm{C}\right)\end{array}$ & $\begin{array}{c}\Delta \mathrm{T} \\
\left({ }^{\circ} \mathrm{C}\right)\end{array}$ & $\begin{array}{c}\mathrm{Tmax} \\
\left({ }^{\circ} \mathrm{C}\right)\end{array}$ & $\begin{array}{c}\Delta \mathrm{T} \\
\left({ }^{\circ} \mathrm{C}\right)\end{array}$ \\
\hline 25 & 47.4 & 22.4 & 63.5 & 38.5 & 68.3 & 43.3 & 94.5 & 69.5 \\
\hline 55 & 80.2 & 25.2 & 91.1 & 36.1 & 95.8 & 40.8 & 117.6 & 62.6 \\
\hline 85 & 110.4 & 25.4 & 120 & 35 & 125.9 & 40.9 & 153.7 & 68.7 \\
\hline
\end{tabular}

The high temperature gradient impedes heat conduction from the $\mathrm{p}-\mathrm{n}$ junction into the environment, that is a cause of increase of junction temperature $T_{j}$ and decrease of consumption power of devices. This phenomenon leads to power difference $(\Delta P)$ between power at referent temperature $T_{c}=25^{\circ} \mathrm{C}$ and at real case temperature $T_{c}$ of devices with high consumption power. Figure 5 shows the experimental data of power difference increase $(\Delta P)$ at the increasing temperature $T_{c}$ from $25^{\circ} \mathrm{C}$ to $100^{\circ} \mathrm{C}$ for HPCOBLED with consumption power in the range of 5-35 W. At high power of $35 \mathrm{~W}$ the decrease of consumption power is significant.

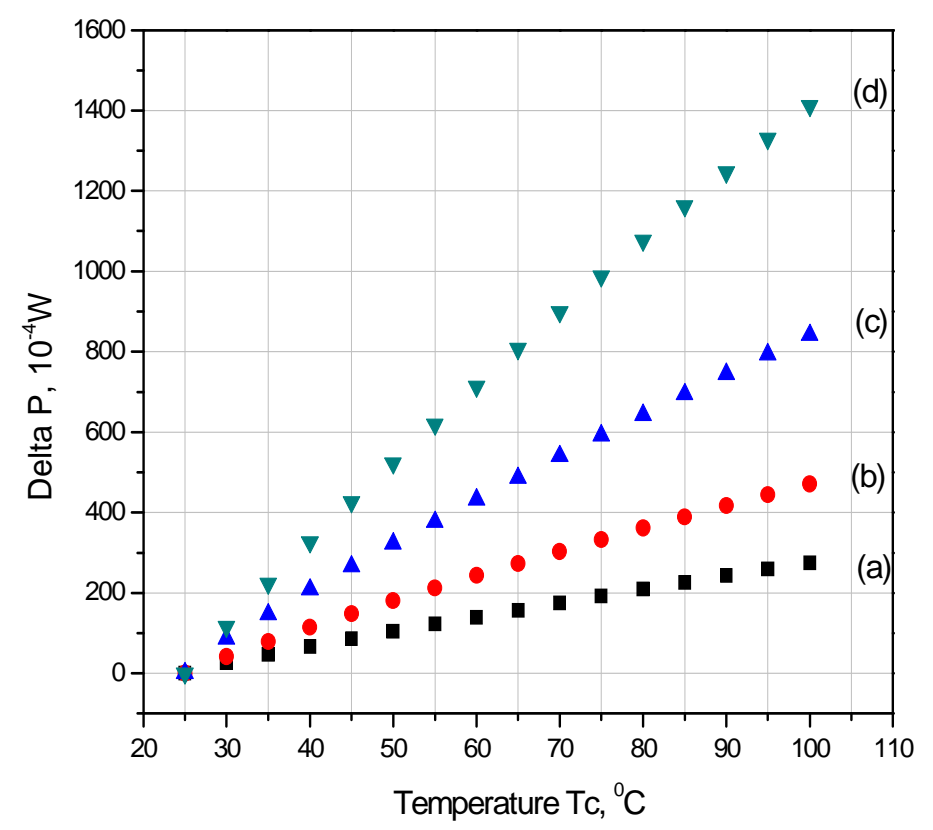

Fig. 5. Dependence of the power difference $(\Delta \mathrm{P})$ on case temperature for HPCOBLED with different consumption powers: (a) $5 \mathrm{~W}$, (b) $10 \mathrm{~W}$, (c) $20 \mathrm{~W}$ and (d) $35 \mathrm{~W}$ 
Fig. 6 shows the dependence of luminous flux on the case temperature of solid-state lighting devices obtained in experiments and by calculation using modified HPCOBLED model.
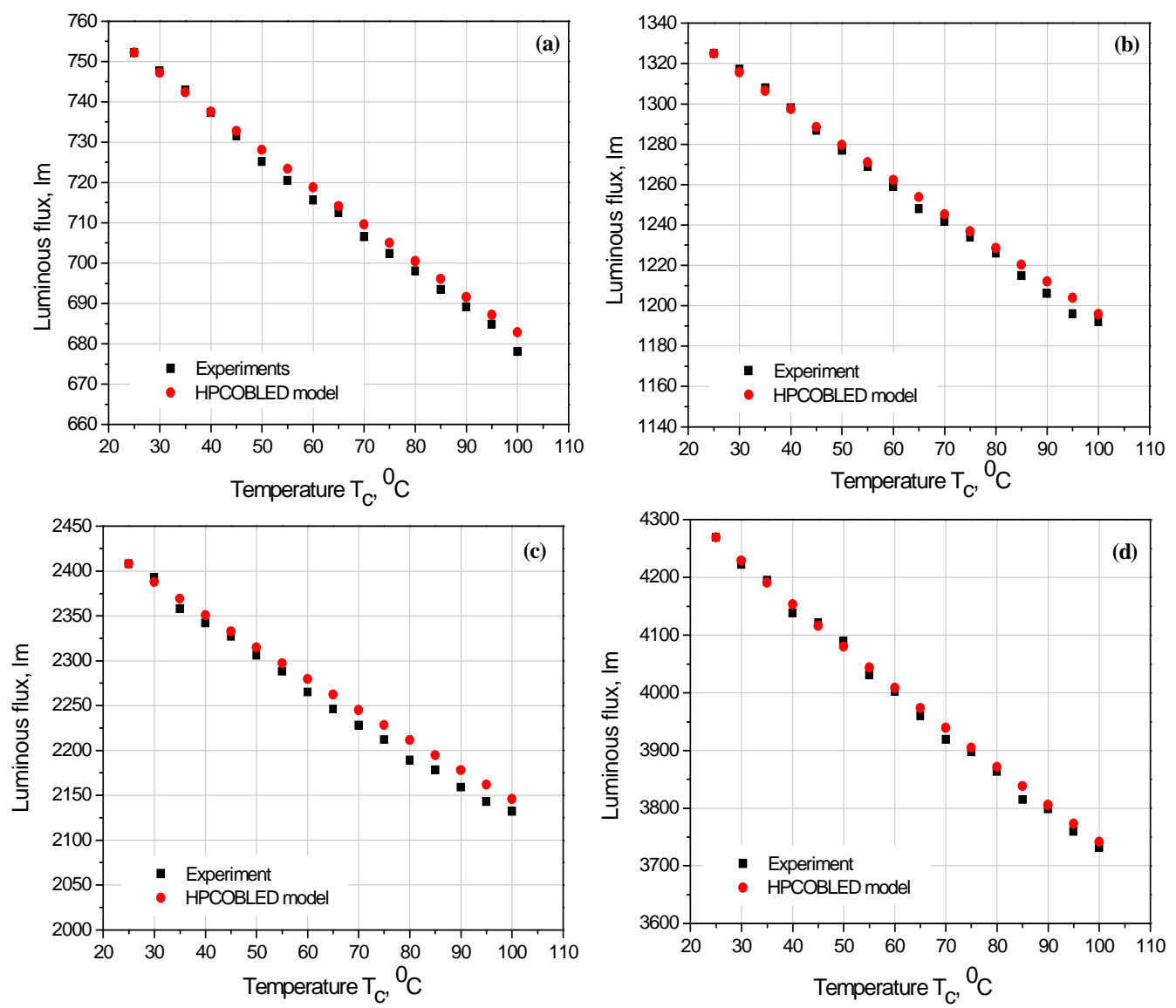

Fig. 6. Graph of the luminous flux versus temperature of HPCOBLED obtained in experiments and by calculation using modified HPCOBLED model for samples: a) $5 \mathrm{~W}$; b) $10 \mathrm{~W}$; c) $20 \mathrm{~W}$; and d) $35 \mathrm{~W}$

It can be seen that the luminous flux calculated by the modified HPCOBLED model almost coincides with the experimental data. This result proves that the proposed HPCOBLED model is a good description for the luminous flux decrease in the solid-state lighting devices with high consumption power.

\section{CONCLUSION}

We study the dependence of the luminous flux irradiated from HPCOBLED on the case temperature $T_{c}$, which is easily measured and controlled in experiment. When temperature $T_{c}$ increases, luminous flux decreases. Particularly, when HPCOBLED is of higher power, the decrease of luminous flux is larger. The reason of this phenomenon can be explained by decrease 
of consumed power of HPCOBLED caused by high temperature gradient from p-n junction to ambient.

The proposed model of HPCOBLED modified from using different Hodapp's model thermal resistance of lighting device, heating radiator and around environment is good description of luminous flux decrease at high power operation. Therefore, the propose model can be used for testing emission characteristics of HPCOBLED at different case temperatures.

\section{ACKNOWLEDGMENTS}

This work was partially supported by the Vietnam Metrology Institute as a part of the research program No. 1198/Q-TDC, dated June 29. 2012.

\section{REFERENCES}

[1] A. I. Zhmakin, Phys. Rep. 498 (4-5) (2011) 189-241.

[2] M.-C. Dubois and Å. Blomsterberg, Energy Build. 43 (10) (2011) 2572-2582.

[3] S. Takamatsu, T. Yamashita, and T. Itoh, "Meter-scale large area LED-embedded Light Fabric for the Application of Fabric Ceilings in Rooms", Microsyst. Technol., 2014.

[4] S. Dutta Gupta and B. Jatothu, Plant Biotechnol. Rep. 7(3) (2013) 211-220.

[5] Mary Yamada, Dan Chwastyk, "Adoption of Light-Emitting Diodes in Common Lighting Applications", report of U.S.Department of Energy, 2013.

[6] J. Li, F. Lin, D. Wang, and W. Tian, Appl. Therm. Eng. 56 (1-2) (2013)18-26.

[7] K. C. Yung, H. Liem, H. S. Choy, and Z. X. Cai, Appl. Therm. Eng. 63 (1) (2014) 105-118,.

[8] H. Wu, K. Lin, and S. Lin, Microelectronics J. 43(4) (2012) 280-287.

[9] J. Wang, Y. Cai, X. Zhao, and C. Zhang, Microelectronics J. 45(2) (2014) 249-255.

[10] Nichia Application Note, SE-AP00003A. Mar. 30. 2012 (www.nichia.com)

[11] Mark W. Hodapp, Semiconductors and Semimetals, Vol 48, Chapter 6, 261 pp., Academic Press, 1997.

[12] www.Lextar.com/COB Thermal Management, Mar.2014 